4. Edzes, H. T., Rupprecht, A. and Berendsen, H. J. C. Biochem. Biophys. Res. Commun. 46 (1972) 790.

5. Ekwall, P. Mol. Cryst. Liquid Cryst. 8 (1969) 157.

6. de Vries, J. J. and Berendsen, H. J. C. Nature 221 (1969) 1139.

7. Johansson, $\AA$. and Drakenberg, T. Mol. Cryst. Liquid Cryst. 14 (1971) 23.

8. Lawson, K. D. and Flautt, T. J. J. Phys. Chem. 72 (1968) 2066.

9. Tiddy, J. T. Nature 230 (1971) 136.

10. Cohen, M. H. and Reif, F. Solid State Physics 5 (1962) 321.

11. Luckhurst, G. R. In Gray, G. W. and Winsor, P. A. Liquid Crystalline Systems, Van Nostrand, Princeton. In press.

12. Rose, M. E. Elementary Theory of Angular Momentum, Wiley, New York 1957.

13. Lawson, K. D. and Flautt, T. J. J. Am. Chem. Soc. 89 (1967) 5489.

14. Wennerström, H., Lindblom, G. and Lindman, B. To be published.

Received April 19, 1972.

\section{Note on the Structure of the Gamma Brass Like $\gamma_{3}$ Phase in the Silver Lithium System}

\section{LARS ARNBERG and SVEN WESTMAN}

Institute of Inorganic and Physical Chemistry, University of Stockholm, S-104 05 Stockholm, Sweden

In a research project at this institute the 1 structures of a number of gamma brass like phases have been studied. These phases generally form in systems between a transition metal ( $T$ or $B^{1}$ according to the nomenclature of Schubert ${ }^{1}$ ) and a nontransition metal from the $B^{2}-B^{4}$ groups of the periodic table. Several different ordering schemes have been observed for the metal atoms on the atomic sites of the general gamma structure type, which are, ${ }^{10}$ in space group $I \overline{4} 3 \mathrm{~m}$, those listed in Table 1 .

A definite tendency has been observed ${ }^{3}$ for the transition metal atoms to con- centrate at the $\mathrm{OT}$ and $\mathrm{OH}$ sites in phases where the transition metal is taken from the $T^{9}, T^{10}$, or $B^{1}$ group and the radius ratio $r(B) / r\left(T\right.$ or $\left.B^{1}\right)$ lies in the range $0.95-1.12$.

No atomic ordering scheme has, so far, been definitely established for a gamma phase with a non-transition metal component outside the $B^{2}-B^{4}$ range. In the Ag-Li system there occur three such phases, all of them cubic. Since silver is a $B^{1}$ metal and the radius ratio $r_{\mathrm{Li}} / r_{\mathrm{Ag}}$ is 1.09 , it was deemed to be of great interest to see whether or not the fact that the nontransition metal is in this case taken from another part of the periodic table would lead to the formation of a differently ordered structure.

Experimental. Preparations of the three phases, $\gamma_{1}, \gamma_{2}$, and $\gamma_{3}$, homogeneous at room temperature in the approximate ranges ${ }^{4}$ $7-13,16-23$, and $26-36$ atomic \% Ag, respectively, were synthesized by fusion of the components in argon of atmospheric pressure. Weighed amounts of the materials ( $\mathrm{Ag}$, powder, Kebo $99.9 \%$ and Li, granular, Merck, sodium content less than $0.05 \%$ ) were melted together in an iron crucible for approximately $15-30$ sec, and allowed to cool without quenching. The loss of $\mathrm{Li}$ by evaporation was found to be very small, and the final compositions were taken to be equal to those calculated from the amounts of $\mathrm{Ag}$ and $\mathrm{Li}$ used. The $\gamma_{1}$ and $\gamma_{2}$ preparations were quite sensitive to atmospheric corrosion and were, moreover, soft so that the pellets could not be easily crushed. Thus, the $\gamma_{3}$-containing charges which were more stable in air, and easier to prepare powder specimens from, were the only ones used for the continued investigation.

X-Ray powder photographs for the deter. mination of lattice parameters were taken in a focusing Guinier-Hägg camera of $80 \mathrm{~mm}$ diameter, with strictly monochromatized $\mathrm{CuK} \alpha_{1}$ radiation $(\lambda=1.54050 \AA)$, and with $\mathrm{KCl}\left(a=6.2919 \AA^{5}\right)$ as an internal standard.

The diffracted intensities were more accurately determined by means of a powder diffractometer ${ }^{11}$ employing crystal monochromatized $\mathrm{Cu} K \alpha$ radiation.

For the calculation of theoretical powder intensities from tentative structure models, Lp-factors were computed according to Sagel, ${ }^{6}$ and the atomic scattering factors and dispersion corrections given by Cromer and Waber, ${ }^{8}$ and Cromer, ${ }^{9}$ respectively, were used.

Results. A preparation which proved to contain $\gamma_{3}$ phase, with only very small 
Table 1. Structural parameters for the $\gamma_{\mathbf{8}} \cdot \mathrm{Ag}, \mathrm{Li}$ phase.

Weighed-in composition

Assumed composition of model

Lattice parameter

Measured density

Calculated density

Unit cell content

Space group

Atomic position and occupancy parameters

IT $(8 \mathrm{Li})$

$\mathrm{O} T(6.4 \mathrm{Ag}+1.6 \mathrm{Li})$

$\mathrm{OH}(9.6 \mathrm{Ag}+2.4 \mathrm{Li})$

$\mathrm{CO}(24 \mathrm{Li})$

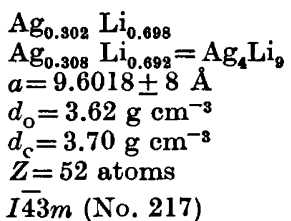

8 (c) $x, x, x ; x=0.10$

8 (c) $x, x, x ; x=-0.17$

12(c) $x, 0,0 ; x=0.35$

$24(g) x, x, z ; x=0.30$ amounts of other phases present, had the composition, density, assumed space group and lattice parameter of the b.c.c. unit cell listed in Table 1.

The atomic position parameters, given in the same table, were assumed to be approximately the same as in, e.g., $\mathrm{Cu}_{5} \mathrm{Zn}_{8}{ }^{2}$ or $\mathrm{Ni}_{2} \mathrm{Zn}_{11},{ }^{7}$ with size factors 1.07 and 1.10 , respectively; and with the same, bodycentered, symmetry.

The lowest $R_{I}=100 \times \sum \| I_{\mathrm{o}}|-| I_{\mathrm{c}}||$ $\sum\left|I_{\mathrm{o}}\right|=10 \%$ was observed for the atomic ordering recordered in Table 1 , implying a completely disordered distribution of 16 silver atoms over the 20 sites of the OT and OH positions.

Models with the same amount of silver differently distributed over these two positions gave higher $R_{I}$ values, ranging up to $17 \%$; a distribution with the OT position completely occupied by $\mathrm{Ag}$ and the $\mathrm{OH}$ position containing $67 \% \mathrm{Ag}, 33 \%$ Li yielded $R_{I}=13 \%$. All other distributions tried yielded much higher values: $R_{I}=32-109 \%$. Inspection of the correspondence between $I_{\mathrm{o}}$ and $I_{\mathrm{c}}$ for the low-angle reflections (notably for $\sum h^{2}=4$ ) also proved these further models to be seriously in error.

In Table 2 are given $I_{\mathrm{o}}$ and $I_{\mathrm{c}}$ for the best structure model obtainable with the synthetic composition given. It may be noted that the calculated intensities of a few unobserved high-angle lines are higher than some actually observed low. angle intensities. The high-angle reflections were generally diffuse, however, and thus not so easily observed. Consequently, observed intensities were only recorded for $\sum h^{2} \leq 66$.

The positions at which the Ag atoms enter in the structure are the expected
Table 2. Intensities for the $\gamma_{3}$-Ag, Li model. $R_{I}=10 \% . I_{\mathrm{o}}$ recorded for $\sum h^{2} \leq 66$.

\begin{tabular}{|c|c|c|c|c|}
\hline$\sum h^{2}$ & $I_{\mathrm{o}}$ & $I_{\mathrm{c}}$ & $\sum h^{2}$ & $I_{\mathrm{c}}$ \\
\hline 2 & 268 & 373 & 68 & 189 \\
\hline 4 & 160 & 276 & 70 & 35 \\
\hline 6 & 8434 & 9352 & 72 & 634 \\
\hline 8 & 647 & 621 & 74 & 188 \\
\hline 10 & - & 192 & 76 & 6 \\
\hline 12 & 602 & 656 & 78 & 372 \\
\hline 14 & 463 & 344 & 80 & 38 \\
\hline 16 & - & 19 & 82 & 29 \\
\hline 18 & 10590 & 10760 & 84 & 197 \\
\hline 20 & - & 36 & 86 & 97 \\
\hline 22 & - & 106 & 88 & 0 \\
\hline 24 & 1406 & 1325 & 90 & 1334 \\
\hline 26 & - & 128 & 94 & 5 \\
\hline 30 & 995 & 599 & 96 & 141 \\
\hline 32 & - & 1 & 98 & 393 \\
\hline 34 & - & 46 & 100 & 28 \\
\hline 36 & 2198 & 1272 & 102 & 555 \\
\hline 38 & - & 352 & 104 & 166 \\
\hline 40 & - & 21 & 106 & 10 \\
\hline 42 & 858 & 858 & 108 & 471 \\
\hline 44 & - & 52 & 110 & 71 \\
\hline 46 & - & 20 & 114 & 781 \\
\hline 48 & - & 327 & 116 & 78 \\
\hline 50 & - & 224 & 118 & 8 \\
\hline 52 & - & 5 & 120 & 618 \\
\hline 54 & 2939 & 2908 & 122 & 285 \\
\hline 56 & - & 6 & & \\
\hline 58 & - & 9 & & \\
\hline 62 & - & 86 & & \\
\hline 64 & - & 9 & & \\
\hline 66 & 1044 & 1264 & & \\
\hline
\end{tabular}

ones, but the distribution over these sites differs somewhat from what has been observed for the "normal" gamma phases." In these, the OT position is first completely

Acta Chem. Scand. 26 (1972) No. 4 
filled with transition metal atoms, and the rest of these atoms statistically distributed over the $\mathrm{OH}$ position.

Acknowledgements. This investigation has been carried out within a research program, sponsored by the Swedish Natural Science Research Council. Part of the funds necessary for the project has been provided by the Tri. Centennial Fund of the Bank of Sweden.

The authors wish to express their sincere gratitude to Professor A. Magnéli for his continued interest in this work and critical reading of the manuscript. We also want to acknowledge the valuable technical assistance of Mrs. G. Winlöf who took the Guinier photographs.

1. Schubert, K. $\dot{K}$ ristallstrukturen zweikomponentiger Phasen, Springer, Berlin 1964.

2. See, e. g., Heidenstam, O. v., Johansson, A. and Westman, S. Acta Chem. Scand. 22 (1968) 653.
3. Westman, S. Chem. Commun. Univ. Stock holm (1972) No. 4. Crystallographic Studies on Gamma Brass Like Phases in Binary Alloy Systems.

4. Freeth, N. E. and Raynor, G. V. J. Inst. Metals 82 (1953-1954) 569.

5. Hambling, P. G. Acta Cryst. 6 (1953) 98.

6. Sagel, K. Tabellen zur Röntgenstrukturanalyse, Berlin 1958, p. 87.

7. Johansson, A., Ljung, H. and Westman, S. Acta Chem. Scand. 22 (1968) 2743.

8. Cromer, D. T. and Waber, J. T. Acta Cryst. 18 (1965) 104.

9. Cromer, D. T. Acta Cryst. 18 (1965) 17.

10. Bradley, A. J. and Thewlis, J. J. Inst. Metals 51 (1933) 131.

11. Kierkegaard, P., Eistrat, K., Gustafsson, K., Johansson, K.-E. and Skancke, A. Structural Studies on Vitreous Compounds. Final Technical Report (1966) DA-91-591EUC-3635.

Received April 22, 1972.

KEMISK BIBLIOTEK

Den $\mathrm{kgl}$. Veterinær - og Landbohøjskole 